\title{
PERSEPSI KEY-PERSONS TERHADAP PROSPEK PENDEKATAN CO-MANAGEMENT DALAM PENGELOLAAN SUMBERDAYA IKAN DEMERSAL DI KABUPATEN REMBANG
}

\author{
Sofyan Eko Putra \\ Magister Ilmu Ekonomi dan Studi Pembangunan, Universitas Diponegoro \\ e-mail: sofyan.eko@gmail.com
}

\begin{abstract}
ABSTRAK
Fishing particularly for demersal fish resources is a business that plays a role in increasing the welfare of coastal communities in the Rembang District Therefore, efforts are needed to manage a sustainable demersal fish resources. This study CoManagement approach with institutional analysis that recommended by ICLARM (Pomeroy and William, 1994 in Susilowati, 1999), which is used to prospect comanagement approach and determine the management form of sustainable demersal fish resources in Rembang District.Co-Management Analysis covers physical attributes, community, institutional, actors, and the attributes of demand and supply
\end{abstract}

Keywords: Co-Management, Demersal Fish, Stakeholders, Rembang District

\section{PENDAHULUAN}

Kabupaten Rembang terletak di wilayah pesisir Pantai Utara, dengan panjang pantai 61,5 $\mathrm{km}$, merupakan kabupaten dengan total produksi perikanan laut terbesar kedua di Provinsi Jawa Tengah. Namun, selama tahun 2002-2006 ratarata pertumbuhan produksi perikanan laut per tahun menurun sebesar $-4,75$ persen.. Penurunan produksi tersebut, berbanding terbalik dengan rata-rata pertumbuhan armada (kapal) penangkap ikan yang meningkat sebesar 7,62 persen per tahun (lihat Tabel 1).
Tabel 1

Perkembangan Produksi, Nilai Produksi, dan Armada Perikanan Laut Kabupaten Rembang Tahun 2002-2006

\begin{tabular}{|c|c|c|c|c|c|c|}
\hline & 2002 & 2003 & 2004 & 2005 & 2006 & $\begin{array}{c}\text { Rata-rata } \\
\text { Pertum- } \\
\text { buhan } \\
(\%)\end{array}$ \\
\hline \multicolumn{7}{|l|}{ Perikanan Laut } \\
\hline Produksi $(000 \mathrm{Kg})$ & $55.281,51$ & $29.579,66$ & $33.152,44$ & $31.434,53$ & 37.907 .10 & \\
\hline Nilai (Juta Rp) & $118.954,56$ & $87.013,58$ & $124.292,71$ & $121.203,42$ & $152.967,51$ & \\
\hline Armada (unit) & 3491 & 4393 & 4246 & 4636 & 4581 & \\
\hline \multicolumn{6}{|l|}{ Pertumbuhan } & $-4,75$ \\
\hline \multicolumn{6}{|l|}{ Produksi (\%) } & 9,93 \\
\hline Nilai $\quad(\%)$ & - & $-26,85$ & 42,84 & $-2,49$ & 26,21 & 7,62 \\
\hline Armada (\%) & - & 25,84 & $-3,35$ & 9,19 & $-1,19$ & \\
\hline
\end{tabular}

Sumber : Dinas Perikanan dan Kelautan Kab. Rembang, 2007 
Hasil penelitian FPIK UNDIP (2002) menunjukkan bahwa pemanfaatan sumberdaya perikanan laut, terutama jenis ikan demersal di Kabupaten Rembang telah mengalami kondisi tangkap lebih (overfishing) atau mencapai 159 $\%$ dari potensi lestarinya. Sedangkan, hasil penelitian Misuari (2006) juga menunjukkan bahwa tingkat pemanfaatan ikan demersal sebesar $82,23 \%$ atau melebihi TAC (Total Allowable Catch) yaitu $80 \%$ dari potensi lestarinya.

Kondisi tersebut berpotensi menurunkan pendapatan nelayan, karena sumberdaya ikan demersal, diantaranya: kakap merah, bawal hitam, kerapu, kakap, manyung, merupakan komoditas unggulan perikanan Kabupaten Rembang. (Profil Perikanan Tangkap Jawa Tengah, 2006).

Pemanfaatan sumber daya ikan demersal yang berlebih (overfishing) di Kabupaten Rembang tidak lepas dari pelanggaran yang dilakukan oleh pemilik kapal (nelayan), yaitu dengan tidak melakukan perpanjangan surat perijinan penangkapan SIUP dan SIPI (Suara Merdeka, 2005). Pelanggaran lain yang dilakukan, diantaranya pelanggaran jalur penangkapan ikan yang merusak biota laut, dan memicu konflik diantara sesama nelayan, serta pemalsuan data dokumen kapal (ukuran GT).

Dalam rangka pemanfaatan sumberdaya ikan demersal yang berkelanjutan di Kabupaten Rembang, diperlukan pendekatan Co-Management untuk menjawab permasalahan pengelolaan sumberdaya ikan demersal di Kabupaten Rembang yang tidak terpisahkan dengan kondisi sosial, ekonomi, budaya dan menemukan bentuk pengelolaan yang sinergi antar stakeholders.

\section{REVIEW LITERATUR}

\section{Konsep Keberlanjutan Dalam Perikanan}

Paradigma pembangunan perikanan pada dasarnya mengalami evolusi dari paradigma konservasi (biologi) ke paradigma rasionalisasi (ekonomi) kemudian ke paradigma sosial. Namun walaupun demikian menurut Charles (1994) ketiga paradigma tersebut masih tetap relevan dalam kaitan dengan pembangunan perikanan yang berkelanjutan. Dengan demikian menurut Charles (1994) pandangan pembangunan perikanan yang berkelanjutan haruslah mengakomodasikan ketiga aspek tersebut di atas. Oleh karenanya konsep pembangunan perikanan yang berkelanjutan sendiri mengandung aspek (Fauzi dan Anna, 2005):

1. Ecological sustainability (keberlanjutan ekologi). Dalam pandangan ini memelihara keberlanjutan stok sehingga tidak melewati daya dukungnya, serta meningkatkan kapasitas dan kualitas dari ekosistim menjadi fokus utama.

2. Socioeconomic sustainabilty (keberlanjutan sosioekonomi). Konsep ini mengandung makna bahwa pembangunan perikanan harus memperhatikan keberlanjutan dari kesejahteraan pelaku perikanan.

3. Community sustainability, mengandung makna bahwa keberlanjutan kesejahteraan dari sisi komunitas atau masyarakat haruslah menjadi perhatian pembangunan perikanan yang berkelanjutan.

4. Institutional sustainability (keberlanjutan kelembagaan). Dalam kerangka ini keberlanjutan kelembagaan yang menyangkut pemeliharaan aspek finansial dan administrasi yang sehat merupakan prasyarat dari ketiga pembanguan berkelanjutan di atas.

\section{Co-Management}

Salah satu bentuk pengelolaan sumber daya yang melibatkan pertisipasi masyarakat dalam mengelola sumberdaya perikanan adalah melalui pendekatan kemitraan. Pomeroy dan Williams (1994), mengemukakan bahwa pendekatan kemitraan (Co-Management) adalah pendekatan berbagi tanggung jawab antara pihak - pihak terkait seperti pemerintah dan masyarakat dalam mengelola sumber daya atau 
lingkungan. Penjelasan singkat mengenai bentuk Co-Management menurut Pomeroy et al. (1994) dalam Nikijuluw (2002) adalah sebagai berikut :

1. Co-Management Instructive, pada bentuk ini, tidak begitu banyak informasi yang saling di pertukarkan antara masyarakat dan pemerintah. Pemerintah dalam hal ini, hanya mengimformasikan kepada masyarakat tentang rumusan-rumusan pengelolaan sungai yang pemerintah rencanakan untuk dilaksanakan.

2. Co-Management Consultative, menempatkan masyarakat pada posisi yang hampir sama dengan pemerintah. Ada mekanisme yang membuat pemerintah berkonsultasi dengan masyarakat. Meskipun masyarakat bisa memberikan masukan pada pemerintah, keputusan tergantung sepenuhnya pada pemerintah.

3. Co-Management Cooperative, bentuk ini menempatkan masyarakat dan pemerintah pada posisi yang sama atau sederajat. Semua tahapan sejak pengumpulan informasi, perencanaan, pelaksanaan, hingga evaluasi dan pemantauan institusi co-management berada di pundak kedua pihak.

4. Co-Management Advocative, pada bentuk ini, peran masyarakat cenderung lebih besar dari peran pemerintah. Peran pemerintah lebih banyak bersifat mendampingi masyarakat atau memberikan advokasi pada masyarakat tentang apa yang sedang mereka kerjakan.

5. Co-Management Informative, di satu pihak peran pemerintah makin berkurang dan di pihak lain peran masyarakat lebih besar. Pemerintah menerapkan delegasi untuk bekerja sama dengan masyarakat dalam seluruh tahapan pengelolaan sungai, sejak pengumpulan data, perumusan kebijakan, implementasi, serta pemantauan dan evaluasi. Hasil pekerjaan delegasi pemerintah dilaporkan atau diinformasikan yang bersangkutan pada pemerintah.

\section{Gambar 1 \\ Bentuk Co-Management}

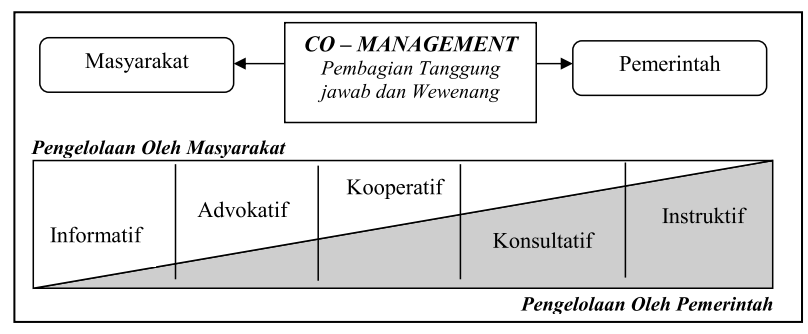

Sumber : Modifikasi dari Pomeroy et al. (1994) Nikijuluw (2002)

Menurut Nikijuluw (2002), pada hakikatnya melalui Co-Management, pemerintah memiliki kesempatan untuk membuktiakan bahwa keputusan yang diambil ternyata bisa secara efektif dilaksanakan. Dimata masyarakat $\mathrm{Co}-$ Management membawa manfaat melalui partisipasi atau keikutsertaan dalam proses pengambilan keputusan.

\section{Sumberdaya Ikan Demersal}

Sumberdaya ikan demersal adalah golongan ikan yang hidupnya di dasar perairan yang terbatas pada daerah sampai kedalaman 100 meter (Direktorat Jenderal Perikanan, 1987). Menurut Dwiponggo, et al dalam Martosubroto, et al (1991), ikan demersal merupakan salah satu kelompok jenis ikan laut yang hidup di dasar perairan atau dekat perairan, ruaya yang tidak terlalu jauh, dan punya aktivitas gerak yang relatif rendah dan lambat.

\section{Kapal Cantrang}

Berdasarkan keterangan DPK Kabupaten Rembang, Misuari dan Sutradji (2006) kapal cantrang merupakan alat tangkap dominan yang digunakan nelayan Kabupaten Rembang untuk penangkapan ikan demersal.

Cantrang atau dogol (danish seine) adalah alat penangkap ikan yang mempunyai sayap, badan, kantong dan dilengkapi dengan tali temali, pelampung, pemberat. Dengan demikian dilihat dari segi bentuk dan konstruksi alat ini mirip 
dengan payang dan digunakan untuk menangkap ikan terutama ikan demersal di perairan teritorial pada jalur I dan II di seluruh perairan Indonesia (Dirjen Pengawasan Sumberdaya Kelautan dan Perikanan, 2004).

\section{Regulasi Sumberdaya Perikanan}

Adapun regulasi pemerintah yang terkait dengan pemanfaatan dan pengelolaan sumberdaya perikanan di Kabupaten Rembang, diantaranya sebagai berikut:

Tabel 2

Regulasi Sumberdaya Perikanan yang Relevan

\begin{tabular}{|c|c|c|}
\hline No & Regulasi & Penjelasan \\
\hline 1 & UU RI No. 31 Tahun 2004 & Perikanan \\
\hline 2 & UU RI No. 32 Tahun 2004 & Otonomi daerah \\
\hline \multirow[t]{2}{*}{3} & Perda Propinsi Jawa Tengah & \multirow[t]{2}{*}{ Perizinan usaha perikanan } \\
\hline & No.3 Tahun 2005 & \\
\hline \multirow[t]{3}{*}{4} & Perda Kabupaten Rembang & Retribusi Surat Tanda \\
\hline & \multirow[t]{2}{*}{ No. 3 Tahun 2005} & Kebangsaan Kecil \\
\hline & & (Pas Kecil) \\
\hline 5 & PP No.4 Tahun1993 & Usaha perikanan \\
\hline \multirow[t]{2}{*}{6} & Kep. Men. Pertanian & \multirow[t]{2}{*}{ Jalur-jalur penangkapan ikan } \\
\hline & No.392/ kpts/ik.120/4/1999 & \\
\hline \multirow[t]{4}{*}{7} & Instruksi Gubernur & \multirow{4}{*}{$\begin{array}{l}\text { Pencegahan/larangan usaha/ } \\
\text { tindakan yang dapat mengaki- } \\
\text { batkan pencemaran/kerusakan } \\
\text { sumberdaya ikan di perairan } \\
\text { umum/laut di Propinsi Daerah } \\
\text { Tk.1 Jawa Tengah }\end{array}$} \\
\hline & Kepala Daerah Tk.1 & \\
\hline & Jawa Tengah 26 Mei 1986 & \\
\hline & No. $523 / 173 / 1986$ & \\
\hline \multirow[t]{2}{*}{8} & Kep. Bupati Rembang & \multirow{2}{*}{$\begin{array}{l}\text { Tim Operasional Patroli Laut } \\
\text { di Wilayah Perairan Laut } \\
\text { Kabupaten Rembang. }\end{array}$} \\
\hline & No.207 Tahun 2004 & \\
\hline
\end{tabular}

Sumber: Berbagai publikasi

\section{METODE PENELITIAN}

\section{Data dan Sampel}

Data primer diperoleh dari responden melalui wawancara yang dipandu dengan kuesioner pada seluruh stakeholders tokoh kunci (key-persons). Sedangkan, data sekunder diperoleh melalui studi literatur terhadap bahanbahan pustaka dan data dari lembaga pemerintah setempat.
Pendistribusian sampel Co-Management, secara purposive berjumlah 30 (sampel kecil), yang meliputi: pemerintah kabupaten (dinas perikanan dan kelautan, dinas perhubungan, dinas lingkungan hidup, dinas kehutanan (mangrove), syahbandar, BAPPEDA), pemerintah desa, (kepala desa Tasikagung dan Tanjungsari), tokoh masyarakat, paguyuban dan kelompok nelayan. Pihak lainya adalah: KUD Saroyo Mino, LSM dan pengusaha, kepala TPI: Tasikagung-1, Tasikagung-2, dan Tanjungsari, dan akademisi: Universitas Diponegoro. Responden merupakan tokoh kunci (key-persons) yang berpengalaman terhadap kegiatan pemanfaatan dan pengelolaan sumberdaya ikan demersal di Kabupaten Rembang. Penelitian ini dilaksanakan pada bulan Juni-Agustus tahun 2007.

Tabel 3

Distribusi Sampel Co-Management: KeyPersons

\begin{tabular}{llc}
\hline \multicolumn{1}{c}{ Uraian } & Jumlah \\
\hline 1. & Pemerintah Kabupaten & 10 \\
2. & Pemerintah Desa & 2 \\
3. & Tokoh masyarakat/nelayan & 7 \\
4. KUD & 3 \\
5. LSM & 2 \\
6. Pengusaha & 2 \\
7. Pengurus TPI & 3 \\
8. Akademisi & 1 \\
\hline
\end{tabular}

Sumber: Data primer, 2007

\section{Metode Analisis}

Metode analisis dalam penelitian ini menggunakan analisis institusional yang direkomendasikan oleh ICLARM (Pomeroy dan William, 1994 dalam Susilowati, 1999). Analisis deskriptif kualitatif dengan menggunakan skala konvensional (1-10): 
a. Skala 1-4 menunjukkan nilai rendah atau sangat tidak setuju (Poor)

b. Skala 5-7 menunjukkan nilai sedang atau biasa-biasa saja (Average)

c. Skala 8-10 menunjukkan nilai tinggi atau sangat setuju (Excellent)

Adapun atribut yang diukur dan dianalisis

dalam penelitian ini, adalah :

1. Atribut Fisik, mengukur kondisi fisik dan teknik perairan. Dalam penelitian ini pengukuran tidak dilakukan, sehingga menggunakan data sekunder.

2. Atribut Masyarakat, mengukur usia, tingkat pendidikan, pekerjaan, dan aktivitas sosial responden masyarakat.

3. Atribut Institusi, mengukur keanggotaan, kohesi group, organisasi yang ada, batas-batas pengelolaan, manfaat dan pengorbanan, partisipasi masyarakat, aturan, legalitas, kerjasama dan kepemimpinan di tingkat masyarakat koordinasi, dan pendelegasian kekuasaan.

4. Atribut Aktor, mengukur peran pemerintah, masyarakat, pengusaha, dan akademisi dalam kegiatan perencanaan, pengendalian, pelaksanaan, dan evaluasi.

5. Atribut Permintaan dan Penawaran, mengukur derajat komersialisasi dan pemanfaatan sumberdaya perikanan. Dalam penelitian ini, aspek derajat komersialisasi dengan menganalisis peluang pasar produk ikan demersal di Kabupaten Rembang.

\section{HASIL PENELITIAN DAN PEMBAHASAN}

\section{Analisis Co-Management: Atribut Fisik}

Atribut fisik dianalisis secara deskriptif berdasarkan hasil penelitian mengenai kondisi fisik pesisir Kabupaten Rembangyang dilakukan oleh BAPPEDA Kabupaten Rembang dan Fakultas Perikanan dan Ilmu Kelautan, UNDIP (2001), adalah:
1. Suhu Permukaan Laut (SPL) perairan berkisar antara $25-29^{\circ} \mathrm{C}$ dan kadar garam (salinitas) berkisar antara 30-34 psu (promil salinity unit). sebaran salinitas rendah antara Kaliori dan Tanjungsari adalah karena adanya aliran masa air tawar dari muara sungai Kali Kurir/ Kali Pricer.

2. Sebaran hara penting N-Nitrat berkisar antara 0,01 sampai $0,138 \mathrm{mg} / 1$ dan P-Fosfat antara 0,01-0,029 $\mathrm{mg} / \mathrm{l}$ dapat dibuat juga pola sebaran $N / P$-ratio, yang secara kaidah ekosistem dipercaya lebih mengindikasikan nilai kesuburan perairan setempat.

3. Berdasarkan analisis citra data satelit Landsat_ETM7 yang diolah diketahui bahwa terjadi proses sirkulasi masa air di perairan pantai dengan tingkat kekeruhan yang cukup tinggi di sepanjang pantai. Hal ini akan menghambat proses fotosintesis.

4. Kepadatan/kelimpahan biomassa fitoplankton di perairan Rembang dan sekitarnya (dari pantai sampai jarak sekitar 25 mil) berkisar antara 12-109 ind/ml adalah cukup baik bagi suatu lingkungan perairan yang subur.

5. Pola kepadatan zooplankton cenderung rendah di sekitar pantai Kaliori dan Tanjungsari dan nampak lebih menyebar dan lebih tinggi kepadatannya ke arah Timur. Hal ini diindikasikan karena Pantai Kaliori dan Tanjungsari terlalu dekat dengan permukiman dan penurunan kualitas perairan.

Analisis Co-Management: Atribut Masyarakat

Berdasarkan kelompok usia dapat dilihat bahwa kelompok usia 41-50 sebesar 53,3 persen dari jumlah responden key-persons, merupakan kelompok umur yang paling banyak berperan dalam kegiatan pengelolaan sumberdaya ikan demersal di Kabupaten Rembang didominasi oleh laki-laki sebesar 93,3 persen. 
Tabel 4

\section{Karakteristik Responden}

\begin{tabular}{|c|c|c|c|}
\hline No & Deskripsi & Frekuensi & $\begin{array}{l}\text { Persentase } \\
(\%)\end{array}$ \\
\hline \multirow[t]{5}{*}{1} & Usia (Tahun) & & \\
\hline & - $<30$ & 1 & 3 \\
\hline & - $31-40$ & 9 & 33 \\
\hline & - $41-50$ & 16 & 53,3 \\
\hline & - $>50$ & 4 & 13,3 \\
\hline \multirow[t]{3}{*}{2} & Jenis Kelamin & & \\
\hline & - Laki-laki & 28 & 93,3 \\
\hline & - Perempuan & 2 & 6,7 \\
\hline \multirow[t]{8}{*}{3} & Asal Pekerjaan & & \\
\hline & - Pemerintah & 12 & 40 \\
\hline & (Kab,Dinas,Desa) & 7 & 23,3 \\
\hline & $\begin{array}{l}\text { - Tokoh Masyarakat/ } \\
\text { Nelayan }\end{array}$ & 3 & 10 \\
\hline & - KUD & 2 & 6,7 \\
\hline & - LSM & 2 & 6,7 \\
\hline & - Pengusaha & 3 & 10 \\
\hline & - Pengurus TPI & 1 & 3,3 \\
\hline \multirow[t]{11}{*}{4} & - Akademisi & & \\
\hline & Pendidikan & 2 & 6,7 \\
\hline & - Tidak tamat/sekolah & 6 & 20 \\
\hline & - $\mathrm{SD}$ & 2 & 6,7 \\
\hline & - SMP & 3 & 10 \\
\hline & - SMU & 1 & 3,3 \\
\hline & - D2 & 7 & 23,3 \\
\hline & - $\mathrm{D} 4 / \mathrm{S} 1$ & 5 & 16,7 \\
\hline & - $\mathrm{S} 2$ & 1 & 3,3 \\
\hline & - $\mathrm{S} 3$ & 3 & 10 \\
\hline & - Abstain & & \\
\hline
\end{tabular}

Sumber: Data primer (diolah), 2007
Tingkat pendidikan key-persons didominasi oleh tingkat pendidikan D4/S1 sebanyak 23,3 persen. Dengan asal pekerjaan terbanyak berasal dari pemerintah yang meliputi: pemerintah kabupaten, dinas, dan desa, yaitu 40 persen dari jumlah responden key-persons.

\section{Analisis Co-Management: Atribut Institusi}

Atribut institusi merupakan komponenkomponen yang terkait dengan institusi sebagai lembaga yang diharapkan mengelola sumberdaya perikanan sesuai dengan fungsi dan manfaat (Alikodra, 2000). Dalam atribut institusi terlihat bahwa kohesi grup $(7,40)$, manfaat dan pengorbanan $(7,32)$, aturan pengelolaan yang ditegakkan $(7,43)$, legalitas untuk berorganisasi $(7,31)$, kerjasama dan kepemimpinan di tingkat masyarakat (7,82), desentralisasi dan pendelegasian kekuasaan $(7,58)$, koordinasi antara pemerintah dan masyarakat $(7,51)$ adalah kondisi kunci penting bagi keberhasilan pendekatan kemitraan (Co-Management) di Kabupaten Rembang, dengan prioritas pada kondisi desentralisasi dan pendelegasian kekuasaan, dan kerjasama dan kepemimpinan di tingkat masyarakat. Nilai prospek keberhasilan pendekatan kemitraan pada pengelolaan sumberdaya ikan demersal di Kabupaten Rembang adalah 78,42 dengan rata-rata 7,13 yang menunjukkan bahwa prospek keberhasilan pendekatan kemitraan adalah sedang atau biasa saja (average). 
Tabel 5

Kondisi Kunci Untuk Keberhasilan Pendekatan Co-Management

\begin{tabular}{|c|c|c|}
\hline No & Kondisi Kunci & Skor \\
\hline 1 & Batas-batas yang jelas & 6,36 \\
\hline 2 & $\begin{array}{l}\text { Keanggotaan yang telah ditentukan secara } \\
\text { jelas }\end{array}$ & 6,52 \\
\hline 3 & Kohesi Grup & 7,40 \\
\hline 4 & Organisasi yang ada & 6,94 \\
\hline 5 & Manfaat dan Pengorbanan & 7,32 \\
\hline 6 & $\begin{array}{l}\text { Partisipasi Masyarakat / Pihak yang } \\
\text { berkompeten }\end{array}$ & 6,23 \\
\hline 7 & Aturan pengelolaan yang ditegakkan & 7,43 \\
\hline 8 & Legalitas untuk berorganisasi & 7,31 \\
\hline 9 & $\begin{array}{l}\text { Kerjasama dan kepemimpinan di tingkat } \\
\text { masyarakat }\end{array}$ & 7,82 \\
\hline 10 & $\begin{array}{l}\text { Desentralisasi dan pendelegasian } \\
\text { kekuasaan }\end{array}$ & 7,58 \\
\hline \multirow[t]{3}{*}{11} & $\begin{array}{l}\text { Koordinasi antara pemerintah dan } \\
\text { masyarakat }\end{array}$ & 7,51 \\
\hline & Total & 78,42 \\
\hline & Rata-rata & 7,13 \\
\hline
\end{tabular}

Sumber: Data Primer (diolah), 2007

\section{Analisis Co-Management: Atribut Aktor}

Peran aktor tokoh kunci (key-persons) memegang peranan penting baik dalam kegiatan pengelolaan maupun pemanfaatn sumberdaya ikan demersal di Kabupaten Rembang. Sehingga, diperlukan evaluasi untuk melihat besarnya peran stakeholders dalam pengelolaan sumberdaya ikan demersal di Kabupaten Rembang (Tabel 6).
Tabel 6

Evaluasi Peran Stakeholder dalam Pengelolaan Sumberdaya Ikan Demersal

\begin{tabular}{|c|c|c|c|c|c|}
\hline \multirow[b]{2}{*}{ No } & \multirow[b]{2}{*}{ Kegiatan } & \multicolumn{4}{|c|}{ Peran Stakeholder } \\
\hline & & Pem & Masy & Peng & $\begin{array}{l}\text { Unv/ } \\
\text { LSM } \\
\end{array}$ \\
\hline \multirow[t]{5}{*}{1} & Perencanaan: & & & & \\
\hline & $\begin{array}{l}\text { a. Penentuan inisiatif tentang } \\
\text { program } / \text { kegiatan }\end{array}$ & 7,88 & 6,37 & 4,07 & 4,53 \\
\hline & b. Penetapan/pengambilan keputusan & 7,98 & 6,20 & 4,13 & 4,13 \\
\hline & $\begin{array}{l}\text { c. Keterlibatan dalam intensitas } \\
\text { pertemuan }\end{array}$ & 7,85 & 6,60 & 4,30 & 4,33 \\
\hline & $\begin{array}{l}\text { d. Derajat penyampaian usul/materi } \\
\text { pertemuan }\end{array}$ & 7,48 & 6,17 & 4,80 & 5,03 \\
\hline \multirow[t]{4}{*}{2} & Pengorganisasian: & & & & \\
\hline & $\begin{array}{l}\text { a. Keterlibatan dalam penyelenggaraan } \\
\text { program / kegiatan }\end{array}$ & 8,00 & 7,03 & 4,27 & 4,47 \\
\hline & $\begin{array}{l}\text { b. Daerah peranan dalam } \\
\text { pengorganisasian program } / \text { kegiatan }\end{array}$ & 7,97 & 6,80 & 4,17 & 4,40 \\
\hline & $\begin{array}{l}\text { c. Frekuensi keterlibatan dalam } \\
\text { aktivitas program/kegiatan }\end{array}$ & 7,93 & 7,00 & 4,23 & 4,50 \\
\hline \multirow[t]{5}{*}{3} & Pelaksanaan: & & & & \\
\hline & $\begin{array}{l}\text { a. Keterlibatan dalam pelaksanaan } \\
\text { program }\end{array}$ & 8,00 & 7,50 & 4,70 & 4,77 \\
\hline & $\begin{array}{l}\text { b. Derajat peranan dalam pengelolaan } \\
\text { program }\end{array}$ & 8,00 & 7,43 & 4,70 & 4,97 \\
\hline & $\begin{array}{l}\text { c. Derajat benefit (manfaat) dari } \\
\text { program }\end{array}$ & 7,47 & 7,60 & 4,80 & 5,15 \\
\hline & $\begin{array}{l}\text { d. Derajat respon terhadap pelaksanaan } \\
\text { program / kegiatan }\end{array}$ & 7,57 & 7,60 & 4,80 & 5,30 \\
\hline \multirow{4}{*}{4} & $\begin{array}{l}\text { Kontrol: } \\
\text { a. } \quad \text { Penglibatan dalam monitoring } \\
\quad \text { (pengawasan) }\end{array}$ & 7,17 & 7,17 & 4,27 & 5.17 \\
\hline & $\begin{array}{l}\text { b. Penglibatan dan evaluasi (target vs } \\
\text { realisasi) }\end{array}$ & 7,60 & 6,67 & 4,27 & 4,83 \\
\hline & $\begin{array}{l}\text { c. Rekomendasi yang diberikan untuk } \\
\text { perbaikan program/kegiatan }\end{array}$ & 7,63 & 6,47 & 4,30 & 4,73 \\
\hline & Rata-Rata & 7,76 & 6,90 & 4,40 & 4,73 \\
\hline
\end{tabular}

Sumber: Data Primer (diolah), 2007 
Stakeholders yang dikategorikan sebagai key-persons terdiri dari: pemerintah daerah, masyarakat sekitar yang memanfaatkan sumberdaya perikanan, pengusaha yang berada disekitar perairan Kabupaten Rembang dan memanfaatkannya, LSM, dan akademisi. Aktor pemerintah yang dievaluasi merupakan pemerintah di tingkat Kabupaten Rembang. Detil dari evaluasi peran stakeholders dalam pengelolaan sumberdaya ikan demersal di Kabupaten Rembang dinilai berdasarkan empat kegiatan, adalah sebagai berikut:

\section{a. Perencanaan}

Peran Stakeholder dalam perencanaan dievaluasi dengan nilai rata-rata (average score) masing-masing: pemerintah $(7,83)$, masyarakat $(6,35)$, pengusaha $(4,33)$, dan universitas/LSM $(4,48)$.

Secara keseluruhan, pemerintah memiliki peran paling baik (Excellent) dalam kegiatan perencanaan: penentuan inisiatif tentang program/ kegiatan $(7,88)$, dan pengambilan keputusan $(7,98)$. Sedangkan, masyarakat memiliki peran biasa saja (average), dengan kontribusi paling baik dalam kegiatan perencanaan: keterlibatan/ intensitas pertemuan $(6,6)$. Hal tersebut disebabkan oleh minimnya inisiatif dan partisipatif masyarakat dalam perencanaan program, sehingga dapat dikatakan pola top-down lebih melekat dalam pengelolaan sumberdaya ikan demersal di Kabupaten Rembang.

\section{b. Pengorganisasian}

PeranStakeholderdalampengorganisasian dievaluasi dengan nilai rata-rata (average score) masing-masing: pemerintah $(7,97)$, masyarakat $(6,93)$, pengusaha $(4,23)$, dan universitas/LSM $(4,47)$.

Secara keseluruhan pemerintah memiliki peran paling baik (Excellent) dalam kegiatan pengorganisasian: keterlibatan dalam penyelenggaraan program/kegiatan $(8,00)$, dan daerah peranan dalam pengorganisasian program/kegiatan $(7,97)$. Sedangkan, masyarakat memiliki peran biasa saja (average) dengan kontribusi peran paling baik dalam kegiatan pengorganisasian: keterlibatan dalam penyelenggaraan program/ kegiatan $(7,03)$, dan frekuensi keterlibatan dalam aktivitas program/kegiatan $(7,00)$. Hal tersebut disebabkan oleh minimnya inisiatif dan partisipatif masyarakat dalam pengorganisasian program, sehingga dapat dikatakan pemerintah merupakan aktor utama dalam kegiatan pengorganisasian pengelolaaan sumberdaya ikan demersal di Kabupaten Rembang.

\section{c. Pelaksanaan}

Peran Stakeholder dalam pelaksanaan dievaluasi dengan nilai rata-rata (average score) masing-masing: pemerintah $(7,78)$, masyarakat $(7,53)$, pengusaha $(4,75)$, dan univ./LSM $(5,08)$.

Secara keseluruhan pemerintah memiliki peran paling baik (Excellent) dalam kegiatan pelaksanaan: keterlibatan dalam pelaksanaaan program $(8,00)$, dan derajat peranan dalam pengelolaan program $(8,00)$. Sedangkan, masyarakat memiliki peran paling baik (Excellent) dalam kegiatan pelaksanaan: derajat benefit (manfaat) dari program $(7,60)$, dan derajat respon terhadap pelaksanaan program $(7,60)$.

Sejajarnya nilai rata-rata evaluasi peran masyarakat $(7,53)$ dan pemerintah $(7,78)$ dalam kegiatan pelaksanaan menunjukkan bahwa masyarakat dan pemerintah merupakan aktor utama dalam kegiatan pelaksanaan pengelolaan sumberdaya ikan demersal di Kabupaten Rembang pada khusunya.

\section{d. Kontrol}

Peran stakeholdesr dalam aspek kontrol dievaluasi dengan nilai rata-rata (average score) masing-masing: pemerintah $(7,47)$, masyarakat $(6,8)$, pengusaha $(4,3)$, dan univ./LSM $(4,9)$.

Secara keseluruhan pemerintah memiliki peran paling baik (Excellent) dalam kegiatan kontrol: rekomendasi yang diberikan untuk program/kegiatan $(7,63)$, dan penglibatan dan evaluasi (target vs realisasi) $(7,6)$. Sedangkan, 
masyarakat memiliki peran biasa saja (marginal) dalam kegiatan kontrol: penglibatan dalam monitoring (pengawasan) $(7,17)$, dan rekomendasi yang diberikan untuk program/kegiatan $(6,47)$. Tingginya nilai rata-rata evaluasi peran pemerintah dinilai cukup baik dalam kegiatan kontrol menunjukkan bahwa pemerintah merupakan aktor utama dalam kegiatan pengelolaan sumberdaya ikan demersal di Kabupaten Rembang.

\section{Analisis Co-Management: Atribut Permintaan dan Penawaran}

Atribut permintaan dan penawaran dapat dilihat dari kondisi penjualan dan pemasaran ikan demersal yang berhasil ditangkap. Dalam menunjang penjualan dan pemasaran produk ikan demersal, peran TPI perlu ditinjau sebagai berikut:

\section{Gambar 2}

\section{Aktifitas Pelelangan Ikan di TPI Tanjungsari dan PPP Tasikagung-2}

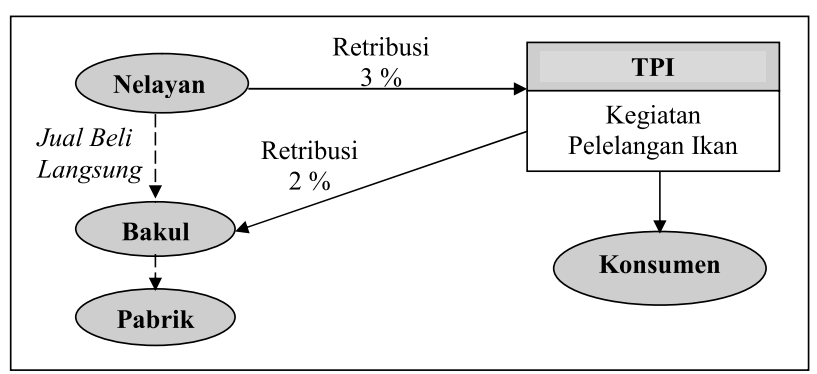

Keterangan: - Aktifitas TPI Aktifitas Non-TPI

Sumber: Data primer (diolah), 2007

Dalam proses penjualan hasil tangkapan di TPI (Tempat Pelelangan Ikan) Tanjungsari. Terdapat dua macam aktifitas penjualan yaitu: mekanisme lelang oleh TPI dan mekanisme langsung oleh bakul (pedagang ikan). Mekanisme lelang dilakukan untuk jenis ikan demersal: petek, ekor kuning, tiga waja, pari atau peh, yang dikenakan retribusi sesuai Perda No. 10 Tahun 2003, yaitu 3 persen kepada nelayan, dan 2 persen kepada bakul, setelah selesai proses pelelangan. Sedangkan, mekanisme langsung, biasanya dilakukan untuk ikan pirik yang digunakan untuk bahan pakan ternak, dan ikan bawal putih yang bernilai ekonomis tinggi $(\bar{x}=$ Rp 80.000 per $\mathrm{kg}$ ) yang disetorkan langsung via bakul kepada pabrik atau usaha pengolahan ikan. Berdasarkan observasi dan wawancara, kinerja TPI Tanjungsari adalah baik (good), karena dapat memenuhi proses penjualan hasil tangkapan nelayan rata-rata sebesar 90 persen dari total tangkapan ikan demersal yang dilelang di TPI.

Perbedaan yang kontras terjadi di PPI Tasikagung-2, berdasarkan observasi dan wawancara, kinerja TPI Tasikagung-2 adalah buruk (poor) karena hanya dapat memenuhi proses penjualan hasil tangkapan nelayan ratarata sebesar 5 persen dari total tangkapan ikan demersal yang dilelang di TPI, sedangkan sisanya sebesar 95 persen penjualan dilakukan via bakul. Hal tersebut disebabkan oleh faktor keterbatasan finansial (keuangan) TPI, sehingga tidak mampu melayani transaksi pelelangan.

Akibat ketidakmampuan tersebut menyebabkan nilai harga pada proses pelelangan ikan di TPI Tasikagung-2 menjadi lebih fluktuatif dibandingkan dengan TPI Tanjungsari yang cenderung stabil sepanjang tahun. Dengan demikian dalam rangka menjaga penjualan hasil perikanan yang menguntungkan nelayan, diperlukan perbaikan kinerja di TPI Tasikagung- 2 .

Dalam hal produksi perikanan tangkap di Kabupaten Rembang, pada umumnya adalah ikan layang, kemudian ikan tembang atau jui, ikan selar dan ikan kembung, yang merupakan ikan jenis pelagis kecil. Adapun hasil tangkapan ikan demersal pada umumnya disetorkan langsung ke pabrik atau usaha pengolahan ikan, diantaranya spesies ikan demersal yang dimaksud adalah kakap merah, dan bawal putih (silver prompt).

Hasil perikanan tersebut dipasarkan sampai Semarang, Yogyakarta, Lampung, Jambi, dan sekitar Sumatera bagian tengah, bahkan sampai ke luar negeri. Namun, ekspor masih dilakukan 
lewat Semarang dan Surabaya, karena di Kabupaten Rembang belum memiliki perwakilan/ agen.

Pada dasarnya peluang pemasaran produk ikan demersal Kabupaten Rembang masih cukup luas, yaitu dengan memperluas penjualan produk ke daerah-daerah potensial pengeluaran konsumsi ikannya tinggi di Provinsi Jawa Tengah. Daerahdaerah yang dimaksud tersebut adalah sebagai berikut: Kabupaten Jepara, Demak, Pati, dan Kudus. Daerah tersebut juga mudah diakses mengingat dareah tersebut posisinya sejalur dengan jalur trasportasi dari dan ke Kabupaten Rembang di dalam jalur transportasi nasional Pantura.

\section{Bentuk Co-Management}

Bentuk co-management pengelolaan sumberdaya perikanan di Kabupatern Rembang hingga saat ini cenderung kepada bentuk Co-Management Consultative (huruf D), yang menempatkan masyarakat pada posisi yang hampir sama dengan pemerintah. Menurut Pomeroy (1994) bentuk Co-Management Consultative cirinya terjadi mekanisme yang membuat pemerintah berkonsultasi dengan masyarakat, meskipun masyarakat bisa memberikan berbagai masukan pada pemerintah, keputusan apakah masukan tersebut harus digunakan, tergantung sepenuhnya pada pemerintah.

\section{Gambar 3}

\section{Bentuk Co-Management Sumberdaya Ikan Demersal di Kabupaten Rembang}

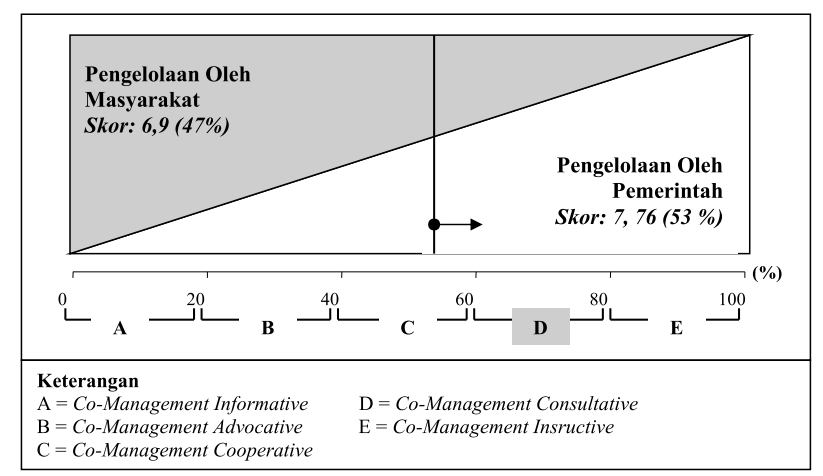

Sumber: Data primer (diolah),

\section{Optimisme Penerapan Co-Management}

Mengenai optimisme key-persons terhadap penerapan pendekatan kemitraan ( $\mathrm{Co}$ Management) dalam pengelolaan sumberdaya ikan demersal di Kabupaten Rembang, sebanyak 90 persen responden menjawab optimis dengan skor 8,33. Mayoritas responden sangat yakin dengan pendekatan Co-Management yang bersifat partisipatif (bottom-up planning) akan memberikan hasil yang paling maksimal dengan pengorbanan yang minimal. Optimisme responden key-persons tersebut merupakan potensi strategis dalam mengelola sumberdaya ikan demersal secara berkelanjutan dan menguntungkan bagi stakeholders.

\section{Gambar 4}

Optimisme Key-Persons Terhadap Penerapan Co-Management

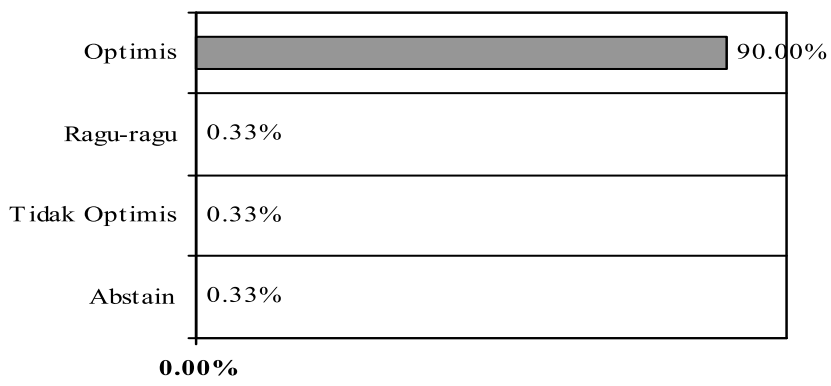

Sumber: Data primer (diolah),

\section{Kelembagaan Pengelolaan Sumberdaya}

Dalam mensukseskan penerapan CoManagement, diperlukan koordinator yang mampu mengelola kelembagaan pengelolaan sumberdaya ikan demersal agar penerapan pendekatan kemitraan (Co-Management) dapat tercapai. Berdasarkan hasil wawancara mengenai siapa yang paling layak menjadi koordinator dalam pengelolaan sumberdaya ikan demersal di Kabupaten Rembang, sebagian besar keypersons menjawab pemerintah paling layak menjadi koordinator pengelolaan sumberdaya ikan demersal sebanyak 46,67 persen, adapun masyarakat dan pengusaha masing-masing 20 persen, dan yang abstain sebanyak 13,33 persen. 
Gambar 5

Persepsi Key-Persons "Siapa yang Paling Layak Menjadi Koordinator?"

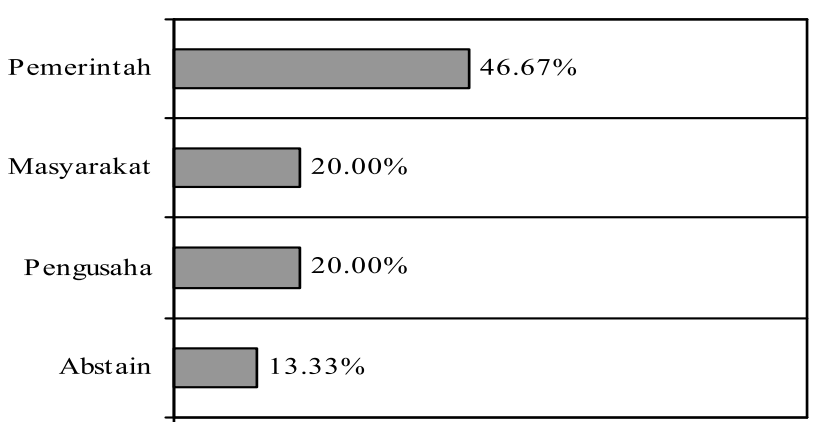

Sumber: Data Primer (diolah), 2007

Berdasarkan wawancara dengan keypersons, maka didapatkan bentuk koordinasi dalam pengelolaan sumberdaya ikan demersal di Kabupaten Rembang dengan penerapan pendekatan Co-Management, sebagai berikut (lihat Gambar 6):

\section{Gambar 6}

\section{Manajemen Pengelolaan Sumberdaya Ikan Demersal Di Kabupaten Rembang:}

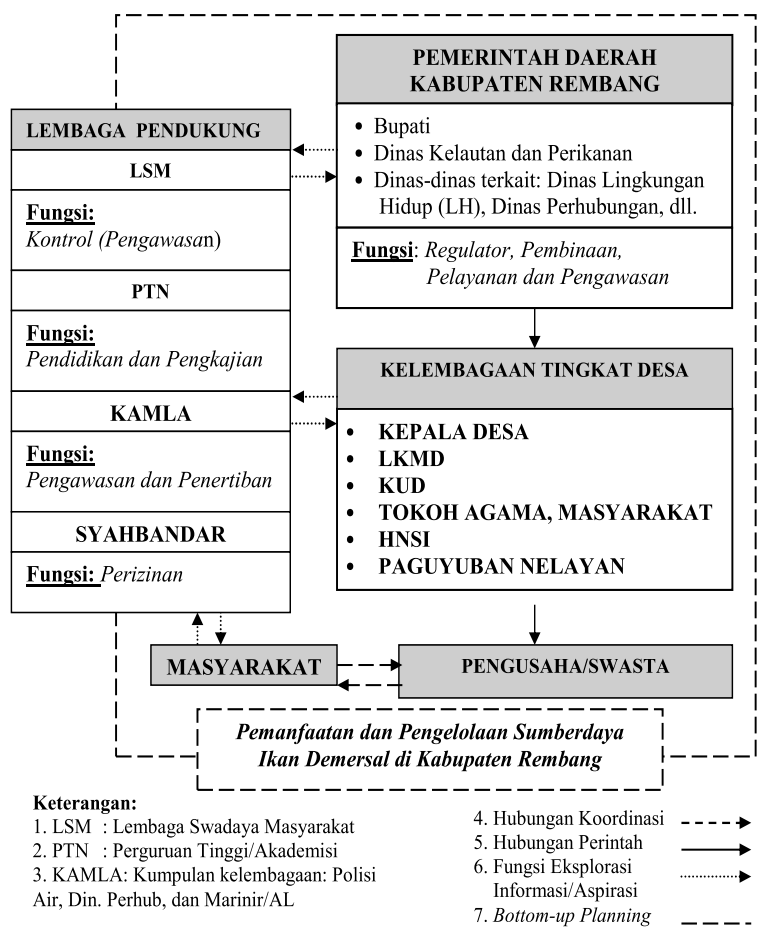

Sumber: Data primer (diolah), 2007
1. Stakeholders, diantaranya: Pemerintah Daerah Kabupaten Rembang (Bupati, Dinas Perikanan dan Kelautan, dan dinas-dinas terkait), lembaga pendukung (LSM, PT/akademisi, KAMLA, syahbandar), kelembagaan tingkat desa (kepala desa, LKMD, KUD, tokoh agama dan masyarakat, HNSI, paguyuban nelayan, masyarakat, dan swasta/pengusaha.

2. Pemerintah daerah Kabupaten Rembang dan kelembagaan tingkat desa dalam melakukan perencanaan, pengorganisasian, pelaksanaan, dan kontrol atau evaluasi harus melibatkan LSM, akademisi, KAMLA, dan syahbandar.

3. Swasta atau Pengusaha diharapkan dapat bertindak sebagai pengelola kegiatan ekonomi yang berkoordinasi dengan masyarakat. Sehingga, diharapkan terciptanya pengelolaan sumberdaya yang efektif dan efisien, ramah lingkungan, dan peningkatan kesejahteraan dan kemadirian masyarakat nelayan.

4. Stakeholders terkoordinasi secara bottom-up planning (partisipatif aktif) yang sinergi dan harmonis dalam lingkup pemanfaatan dan pengelolaan sumberdaya ikan demersal di Kabupaten Rembang.

5. Semakin meningkatnya kemandirian masyarakat (Excellent on economic and environment), maka Co-Management Informative akan terwujud.

\section{KESIMPULAN DAN SARAN}

1. Penilaian prospek keberhasilan pendekatan kemitraan pada sumberdaya ikan demersal di Kabupaten Rembang adalah sedang atau biasa-biasa saja (average), dengan nilai ratarata 7,13 .

2. Bentuk Co-Management pengelolaan sumberdaya ikan demersal di Kabupaten Rembang adalah $\mathrm{Co}$-Management Consultative. 


\section{DAFTAR PUSTAKA}

Alikodra, H.S, 2001, Konsep Pengelolaan Daerah Aliran Sungai Terpadu, dalam Prosiding Diskusi Panel Sistem Pengelolaan Terpadu Daerah Aliran Sungai. Kerjasama Tehnik Pemerintah Indonesia-Pemerintah Federal Jerman. Kantor Kementrian Negara Lingkungan Hidup/BAPEDAL-GTZ, Jakarta

Anderson, LG, 1986, The Economic of Fisheries Management, The John Hopkins University: USA.

Bagian Proyek Pengembangan Teknologi Penangkapan Ikan-Balai Pengembangan Penagakapan Ikan,1996, KlasifikasiAlat Penangkap Ikan yang Disesuaikan untuk Perairan Indonesia, Semarang

Dwiponggo, Aloysius, 1992, Pengkajian Perkiraan Potensi Sumberdaya Perikanan dan Tingkat Pengusahaanya di Perairan Utara Jawa, Balai Penelitian Perikanan Laut. Departemen Perikanan, Jakarta

Dinas Kelautan dan Perikanan Kabupaten Rembang, 2007, Profil Perikanan Kabupaten Rembang, Rembang (tidak dipublikasikan)

Dirjen Pengawsan Sumberadaya Kelautan dan Perikanan, 2004, Standar Operasional dan Prosedur Pengawasan Penangkapan Ikan, Jakarta.

Fakultas Perikanan dan Ilmu Kelautan, Universitas Diponegoro, 2002, Pedoman Pengelolaan Sumberdaya Pesisir dan Laut Spesifik Lokal di Pantai Utara Jawa Tengah, Semarang

Fakultas Perikanan dan Ilmu Kelautan, Universitas Diponegoro, 2003, Pengembangan Basis Data Kelautan Dan Perikanan, Semarang
Fakultas Perikanan dan Ilmu Kelautan, Universitas Diponegoro, 2001, Pemetaan Digital Dan Sumberdaya Hayati Wilayah Pesisir Kabupaten Rembang, Kerjasama dengan BAPPEDA Kabupaten Rembang, Semarang

Fauzi dan Anna, 2005, Permodelan Sumberdaya Perikanan dan Kelautan, PT. Gramedia Pustaka: Jakarta

Fauzi, Akhmad, 2005, Kebijakan Perikanan dan Kelautan: Isu, Sintesis, dan Gagasan, Gramedia Pustaka: Jakarta

Misuari, 2006, Pemanfaatan Sumberdaya Perikanan Cantrang Sesuai Dengan Code of Conduct For Responsible Fisheries (CCRF) di Perairan Rembang Jawa Tengah, Skripsi, Fakultas Perikanan dan Ilmu Kelautan, Universitas Diponegoro, Semarang (tidak dipublikasikan)

Nikijuluw Victor, P.H, 2002, Rezim Pengelolaan Sumberdaya Perikanan, Pustaka Cisendo, Jakarta

Pomeroy,Robert S. dan William Meryl J.,1994, Fisheries Co-Management and Small-Scale Fisheries: A Policy Brief, ICLARM,Manila

Susilowati, Indah, 2006, Keselarasan dalam pemanfaatan dan Pengelolaan Sumberdaya Perikanan Bagi Manusia dan Lingkungan, dalam Pidato Pengukuhan Guru Besar Fakultas Ekonomi Universitas Diponegoro, Semarang 2002,Will Co-Management Approach Bring A Good Prospect For Babon River Management In Semarang, Central JavaIndonesia?, dalam Journal of Coastal Development, Vol.1,Nom.1,Oktober 2002, Universitas Diponegoro, Semarang 
,1999,An Analysis of CoManagement Fisheries In West Sumatra Province, Indonesia: A Case Study of Ikan Larangan, Reserach Report, International Center For Living Aquatic Resource Management, Manila, Philipines 1998, A Prospect of Introducing Co-Management System In Natural Resource Management In Indonesia: A Closer Look at Fisheries, Tanzanian Journal of Population Studies and Development Vol. 5, No: $1 \& 2$
Sutardji, 2006, Potensi dan Tingkat Pemanfaatan Sumberdaya Ikan di Perairan Rembang Jawa Tengah, Skripsi, Fakultas Perikanan dan Ilmu Kelautan, Universitas Diponegoro, Semarang (tidak dipublikasikan)

Kapal Cantrang di Tahan Di Surabaya,www. suaramerdeka.com,Download:9/8/07 